\title{
Gastroesophageal reflux episodes in asthmatic patients and their temporal relation with sleep architecture
}

\author{
L. Mello-Fujita1, S. Roizenblat ${ }^{1}$, C.R. Frison², L. Rodrigues Junior ${ }^{3}$, S. Garbuio1, \\ S. Tufik ${ }^{1}$ and L.R.A. Bittencourt ${ }^{1}$ \\ 1Departamento de Psicobiologia, ${ }^{2}$ Departamento de Pneumologia, ${ }^{3}$ Departamento de Gastroenterologia, \\ Escola Paulista de Medicina, Universidade Federal de São Paulo, São Paulo, SP, Brazil
}

Correspondence to: L.R.A. Bittencourt, Rua Napoleão de Barros, 925, Vila Clementino, 04024-002 São Paulo, SP, Brasil

Fax: +55-11-5572-5092. E-mail: lia@psicobio.epm.br

Gastroesophageal reflux (GER) is common in asthma patients and can contribute to sleep disruption. The aim of the present study was to determine the time-related distribution of GER events together with their impact on sleep in asthmatic subjects with GER disease symptoms. The inclusion criteria were: 18-65 years, controlled moderate to severe asthma and GER-compatible clinical evidence. The exclusion criteria were: chronic obstructive lung disease, smoking, infections of the upper airways, use of oral corticosteroids, other co-morbidities, pregnancy, sleep-related disorders, night-time shift work, and the use of substances with impact on sleep. Asthmatic patients with nocturnal symptoms were excluded. All-night polysomnography and esophageal $\mathrm{pH}$ monitoring were recorded simultaneously. Of the 147 subjects selected, 31 patients and 31 controls were included. Seventeen patients were classified as DeMeester positive and 14 as DeMeester negative. Both groups displayed similar outcomes when general variables were considered. Sleep stage modification one minute prior to GER was observed in the DeMeester-positive group. Awakening was the most frequent occurrence at GER onset and during the 1-min period preceding $38 \%$ of the nocturnal GER. Sleep stage 2 was also prevalent and preceded $36 \%$ of GER events. In the DeMeester-negative group, awakening was the most frequent response before and during GER. Modifications in sleep stages, arousals or awakenings were associated with $75 \%$ of the total GER events analyzed during the period of one minute before and after the fall of esophageal pH below 4 in the DeMeester-positive group. These data provide evidence that sleep modifications precede the GER events in asthmatic patients.

Key words: Asthma; Gastroesophageal reflux; Polysomnography; Sleep

Publication supported by FAPESP.

Received December 15, 2006. Accepted December 13, 2007

\section{Introduction}

Occasional regurgitation and heartburn due to gastroesophageal reflux (GER) are frequent in the general population. GER disease refers to the presence of symptoms which are secondary to the reflux of gastric content through the esophagus with or without signs of esophageal mucosa lesions (1). In more severe manifestations, GER seems to be related to recurrent and long-lasting reflux episodes which occur even during sleep (2). The increase in the transdiaphragmatic pressure, which occurs in the initial phases of sleep, may predispose patients to GER (3). The literature also highlights a greater frequency of GER occurring during arousals and the awakening period, but being markedly absent during rapid eye movement (REM) sleep $(4,5)$.

Approximately 50 to $70 \%$ of asthmatic subjects regularly display GER symptoms (6-9). Esophageal mobility alterations occur in $82 \%$ of cases due to longer periods of contact between the esophageal mucosa and gastric acid 
(10). Sleep abnormalities frequently detected in these subjects may not only result from asthma aggravation during the night $(11,12)$ but may also stem from GER events $(10,13)$ as reported by Goodall et al. $(6)$ in a doubleblind crossover study of 20 asthmatic patients. In that particular study, the investigators reported the beneficial effect of cimetidine on the night symptoms of asthma and GER. Additionally, reproduction of the alterations in nighttime breathing patterns by infusing acid solution into the distal esophagus of asthmatic patients with esophagitis has been reported $(14,15)$. However, the relationship between asthma, GER and disordered sleep is not understood. In a controlled study of nine patients with asthma, Hughes et al. (4) failed to find a higher incidence of GER or any impact of the latter on respiratory and sleep parameters, since GER episodes occurred mainly during arousals or waking periods. Similarly, in a study based on simultaneous and continuous recording of $\mathrm{pH}$ and lower airway resistance, Tan et al. (16) failed to identify any impact of GER on day- or night-time asthma attacks.

Assuming that, before their detection, GER events can contribute to sleep disruption in asthma, the present study was conducted with the aim of determining the time-related distribution of GER events together with their impact on sleep in asthmatic subjects.

\section{Patients and Methods}

\section{Patients}

From 2000 to 2002, 147 subjects with moderate/severe asthma were recruited from the outpatient Pneumology Unit of São Paulo Federal University (UNIFESP). Patient selection was based on the Global Initiative for Asthma (17). These subjects fulfilled the inclusion criteria, i.e., age 18-65 years, a diagnosis of moderate to severe bronchitic asthma controlled with regular inhalatory corticosteroids at doses equivalent to $1000 \mu \mathrm{g} /$ day beclomethasone by a metered dose inhaler for at least 60 days, and the presence of GER-compatible clinical evidence (18), such as heartburn symptoms or regurgitation up to two weeks before the initial interview. The exclusion criteria were: a diagnosis of chronic obstructive lung disease; a history of smoking during the previous year (even if the individual had already stopped smoking); infectious diseases of the upper airways during the previous 6-month period; use of oral corticosteroids; presence of co-morbidities, particularly gastrointestinal, neurologic or metabolic diseases; pregnancy; illiteracy; alcoholism; sleep-related disorders; night-time shift working, and the use of medications with an impact on sleep. The exclusion of asthmatic subjects who complained of night-time or morning aggra- vation over 20 days prior to the initiation of the project was based on the decision to minimize the influence of any other respiratory condition on our data.

The study also included anthropometric and polysomnography (PSG) data from 31 healthy controls with sleep disturbances but without respiratory or gastroesophageal complaints, matched for sex and age, taken from the database of the Sleep Medicine and Biology Discipline, UNIFESP.

The study was approved by the Research Ethics Committee of UNIFESP. The participants were provided with all the relevant information and gave written informed consent to participate in the research on a voluntary basis.

\section{Sleep study}

All 31 patients included were invited to the Sleep Laboratory of UNIFESP for an initial clinical sleep evaluation by first-night basal full PSG followed by placement of a $\mathrm{pH}$ catheter and a subsequent second night of full PSG.

The computerized Oxford System ${ }^{\mathrm{TM}}$ (UK) and Sleep Analyzer Computer (version 9.3) were used for sleep recordings, carried out for at least $7 \mathrm{~h}$. Of the 16 channels of the system, three were used for the electroencephalogram (C3-A2, C4-A1, O1-A2), two for the electroculogram (right and left), two for the electromyogram (chin and the anterior tibialis muscle), one for the electrocardiogram (V2 modified), and the remaining ones for body position sensor, nasal thermistor, microphone, and abdominal and thoracic belts. Pulse oximetry (Ohmeda ${ }^{\mathrm{TM}}$, USA) was also carried out. After the recordings, the sleep stages were analyzed visually and blindly by an experienced investigator at a sampling frequency of $256 \mathrm{~Hz} /$ channel, in consecutive epochs of $30 \mathrm{~s}$ according to standardized criteria (19). The percents of sleep stages were measured as percent total sleep time and the percents of wake after sleep onset as percent total recording time. Respiratory events (20) and arousals (21) were also scored.

\section{Gastroesophageal study}

Esophageal pH monitoring (Zinetics, Meditronic Medizinelektronik GmbH, Hohen, Neuendorf, Germany) was initiated immediately after the basal PSG, at 8:00 am with subjects in the fasting condition. The two-channel $\mathrm{pH}$ catheter was introduced nasally and placed $5 \mathrm{~cm}$ from the lower esophagus, tracked by esophageal manometry. During the study period, catheterized subjects recorded eating times on a daily basis (beginning and end of food ingestion period), time spent lying down, the taking of regular medication, along with all symptomatic periods. Patients were instructed to maintain their usual level of physical activity and meal characteristics, with the exception of acidic foods. Patients were not allowed to lie down 
during the day, when $\mathrm{pH}$ monitoring occurred. During the night, pHmetry recordings were performed concomitantly with the second PSG recording. All data obtained were stored in a database. The recording and analysis of GER events were performed by the Esophogram software (Gastrosoft, Irving, TX, USA).

Acid GER was defined as a drop of $\mathrm{pH}$ below 4, with a minimum duration of $15 \mathrm{~s}$ (22). Patients were classified according to the criteria proposed by DeMeester et al. (22) based on the following parameters measured on the distal electrode: total number of reflux episodes, number of reflux episodes with $\mathrm{pH}$ below 4 lasting $5 \mathrm{~min}$ or more, duration in minutes of the longest reflux episode, percent of total time with $\mathrm{pH}$ below 4 , percent of time with $\mathrm{pH}$ below 4 in the orthostatic position period, and percent of time with $\mathrm{pH}$ below 4 in the supine position period. Subjects were classified as DeMeester positive for scores of 14.72 or more and as DeMeester negative for scores below 14.72. According to the position during reflux, GER was classified as orthostatic or supine. GER episodes during sleep were analyzed according to time of reflux, duration in seconds, sleep stage at the time of reflux and during the period of 1min that preceded it. Sleep fragmentation was defined in terms of changes in sleep stage, arousals and awakenings at the time of GER and during the 1-min period that preceded it. Asthma exacerbation related to GER episodes was clinically evaluated for each episode, and again in the morning, upon completion of both sleep recordings.

\section{Statistical analysis}

The normality of data distribution was submitted to the Kolmogorov-Smirnov test. Descriptive data are presented as mean \pm SD for parametric data and median (interquartile range: 25th and 75th percentiles) for non-parametric ones. Comparisons between DeMeester-positive and -negative patients regarding the quantitative variables were performed by the Student $t$-test or by the Mann-Whitney Utest when the distribution of the data was not normal. Qualitative variables were analyzed by the chi-square or Fisher test as appropriate. The level of significance adopted was 0.05 . The 'Statistica', Statistical package version 5 was used for data processing.

\section{Results}

Of the 147 subjects selected, only 31 completed the trial, while the others dropped out because they presented one or more of the following features during the study: infectious diseases of the upper airways (8 patients), asthma aggravation (30 patients), and being absent during one or more phases of the study (78 patients).
The 31 patients included in the study (age: $47 \pm 10$ years; range: 18-65 years, 28 females, 3 males) exhibited basal forced expiratory volume in the first second $\left(F E V_{1}\right)$ of $1.6 \pm 0.6 \mathrm{~L} / \mathrm{min}$, and a DeMeester index of $15 \pm 38$. In comparison to the 31 healthy controls matched for sex and age (age: $47 \pm 9$ years; range: 18-65 years, 28 females, 3 males), the body mass index (BMI) of the asthmatic subjects was higher (30 \pm 8 vs $21 \pm 2 \mathrm{~kg} / \mathrm{m}^{2}$, respectively, $\mathrm{P}<$ $0.001)$. Of the 31 asthmatic subjects, $9(29 \%)$ had a BMI $>25 \mathrm{~kg} / \mathrm{m}^{2}$ and $13(42 \%)$ a BMI $>30 \mathrm{~kg} / \mathrm{m}^{2}$, whereas only 1 of the control group volunteers displayed a BMI higher than $25 \mathrm{~kg} / \mathrm{m}^{2}\left(27 \mathrm{~kg} / \mathrm{m}^{2}\right)$.

In comparison to the control group, asthmatic patients presented significantly lower total sleep time $(434.2 \pm 44.3$ vs $360.2 \pm 38.6 \mathrm{~min}, \mathrm{P}<0.001)$, sleep efficiency $(92.8 \pm 4.6$ vs $81.9 \pm 8.44 \%, P<0.001)$, percent REM sleep $(23.1 \pm 3.2$ vs $19.5 \pm 6.2 \%, P=0.006)$, and also higher mean values for arousals $(4.8 \pm 5.7$ vs $18 \pm 13.7 / \mathrm{h}, \mathrm{P}<0.001)$, and percent total sleep time with blood oxygen saturation below $90 \%(0.2 \pm 0.2$ vs $0.8 \pm 2.2 \%, \mathrm{P}<0.001)$.

Among the 31 asthmatic subjects, the median number of GER episodes, detected by esophageal $\mathrm{pH}$ recording, was greater during the day in the orthostatic position than during the night in the supine position (35, range 1-262, vs 5 , range $0-48$, respectively, $\mathrm{P}<0.001$ ).

Seventeen of the 31 asthmatic subjects were DeMeester positive while 14 were DeMeester negative, with no significant difference between groups in terms of sex, age, BMI, or $\mathrm{FEV}_{1}$ values. Additionally, there was no significant difference between the two basal $\mathrm{FEV}_{1}$ values obtained after sleep recording for each individual.

Over the 24-h period encompassing GER recordings, the DeMeester-positive group exhibited a total of 1596 GER episodes, 1262 (79\%) of which occurred in the orthostatic position. In the DeMeester-negative group, a significantly lower number of GER episodes was detected, i.e., 254 events $\left(\chi^{2}=17.22, \mathrm{P}<0.001\right), 229(90 \%)$ of which occurred in the orthostatic position.

No significant difference in PSG parameters was detected between the DeMeester-positive and -negative groups (Table 1). Sleep oscillations and variation in esophageal $\mathrm{pH}$ were detected in 10 of the 17 DeMeester-positive subjects, and in 7 of the 14 DeMeester-negative ones, corresponding to a total of 167 GER episodes in the DeMeester-positive group and 12 in the DeMeester-negative group. The data for the remaining patients were not studied due to artifacts in sleep recordings. Modifications in sleep pattern were evaluated at the time when the esophageal $\mathrm{pH}$ level fell below 4.0 , along with readings during the minute preceding the onset of GER (Table 2). In the DeMeester-negative group, only one GER was fol- 
lowed by arousal. Awakening was the most prevalent condi- in 72 of the 103 GER that occurred during sleep, sleep tion at the time of a GER event and during the minute that stage modification or arousal events were detected throughpreceded it ( $P=0.01$ in both groups). Although awakening out the period from $1 \mathrm{~min}$ before to $1 \mathrm{~min}$ after the GER was also the most prevalent condition in the DeMeester- event: of 18 GER in stage 1 non-REM sleep, $94 \%$ were positive group, stage 2 was also a prevalent sleep stage associated with changes to a superficial pattern of sleep ( $P$ during the $1 \mathrm{~min}$ that preceded GER (Table 2). In this group, <0.001, Fisher test), and this was the case for $78.3 \%$ of 60 GER events in stage 2 non-REM sleep $\left(\chi^{2}=39.14, \mathrm{P}<\right.$

Table 1. Sleep characteristics of asthmatic subjects according to the DeMeester index.

\begin{tabular}{lcc}
\hline Variables & $\begin{array}{c}\text { DeMeester } \\
\text { negative } \\
(\mathrm{N}=14)\end{array}$ & $\begin{array}{c}\text { DeMeester } \\
\text { positive } \\
(\mathrm{N}=17)\end{array}$ \\
\hline TST (min) & $362.1 \pm 37.8$ & $358.7 \pm 40.4$ \\
min-max & $288-404$ & $294-437$ \\
Efficiency (\%) & $84.2 \pm 7.7$ & $80.1 \pm 8.8$ \\
min-max & $70.2-93.7$ & $68.6-95.9$ \\
Stages 1 and 2 (\%TST) & $56.5 \pm 8.9$ & $60.9 \pm 11.8$ \\
min-max & $44.5-74.4$ & $47.6-90.4$ \\
Stages 3 and 4 (\%TST) & $23.5 \pm 6.4$ & $19.7 \pm 8.4$ \\
min-max & $7.4-30.5$ & $5.3-36.8$ \\
REM (\%TST) & $19.96 \pm 5.5$ & $19.2 \pm 6.9$ \\
min-max & $8.3-27.2$ & $4.3-29.6$ \\
Brief arousal index events (N/h) & $20.9 \pm 11.9$ & $18.9 \pm 9.9$ \\
min-max & $5.3-50.8$ & $8.5-40.5$ \\
SAT O $2<90$ mmHg (\%TST) & $4.7(9.8)$ & $0.8(1.3)$ \\
min-max & $0-16$ & $0-4$ \\
AHI (events/h) & $2.4(3)$ & $1.6(5.1)$ \\
min-max & $0-23.4$ & $0-26$ \\
\hline
\end{tabular}

Data are reported as means $\pm S D$, minimum and maximum, or median interquartile range (25th and 75th percentiles). TST $=$ total sleep time; REM = rapid eye movement; SAT = saturation; $\mathrm{AHI}=$ apnea-hypopnea index. There were no significant differences between groups (Student $t$-test for independent samples or Mann-Whitney U-test).
0.001 ) and for $85.7 \%$ of 7 GER events during REM sleep ( $P$

$=0.04$, Fisher test; Figure 1). No significant influence of GER on sleep was observed in stages 3 and 4. Arousals preceded the detection of 22 GER episodes, and followed 28 episodes (Table 2). Modifications in sleep showed no significant relationship with asthma exacerbation, since the subjects did not exhibit cough, chest wheezing or dyspnea symptoms, nor did they need to use asthma relief medication during the study period.

\section{Discussion}

This study was designed to evaluate the role of GER in sleep abnormalities in patients with asthma and GERrelated symptoms, using all-night PSG recordings along with a 24-h monitoring of esophageal $\mathrm{pH}$. In comparison to a matched control group without respiratory or gastrointestinal symptoms, mean BMI value was higher in the subjects with asthma and GER symptoms. These subjects presented evidence of sleep fragmentation, reduction in blood oxygen saturation, but a normal apnea-hypopnea index.

Although higher BMI values were observed in the group of asthmatics than in controls, the findings of this study are applicable to asthmatics in general, since the prevalence of obesity in asthma has been described $(24,25)$. Considering the role of obesity as a risk factor both for GER disease (26) and sleep-related breathing disorders (27),

Table 2. Influence of gastroesophageal reflux on sleep.

\begin{tabular}{|c|c|c|c|c|}
\hline & \multicolumn{2}{|c|}{ DeMeester negative $(N=7) 12$ GER episodes } & \multicolumn{2}{|c|}{ DeMeester positive $(N=10) 167$ GER episodes } \\
\hline & 1 min before GER episodes & During GER episodes & 1 min before GER episodes & During GER episodes \\
\hline Stage 0 & $9(75 \%)^{*}$ & $9(75 \%)^{*}$ & $64(38.3 \%)^{+}$ & $95(56.9 \%)^{+}$ \\
\hline Stage 1 & 0 & 0 & $18(10.8 \%)$ & $12(7.2 \%)$ \\
\hline Stage 2 & $2(16.7 \%)$ & $2(16.7 \%)$ & $60(35.9 \%)$ & $45(26.9 \%)$ \\
\hline SWS & 0 & 0 & $18(10.8 \%)$ & $13(7.8 \%)$ \\
\hline REM & $1(8.3 \%)$ & $1(8.3 \%)$ & $7(4.2 \%)$ & $2(1.2 \%)$ \\
\hline Arousal & 0 & $1(100 \%)$ & $22(42.0 \%)$ & $28(56.0 \%)$ \\
\hline
\end{tabular}

GER = gastroesophageal reflux; SWS = slow wave sleep; REM = rapid eye movement.

${ }^{*}$ The DeMeester-negative group presented more stage 0 sleep 1 min before and during GER episodes than other sleep stages $(P<$ 0.01; Fisher and $\chi^{2}$ tests). ${ }^{+}$The DeMeester-positive group presented more stage 0 sleep 1 min before and during GER episodes than other sleep stages $\left(\mathrm{P}=0.0007 ; \chi^{2}\right.$ test). 
we propose that this aspect may have influenced some of the results of the present study, including the reduction in blood oxygen saturation possibly caused by a certain degree of hypoventilation. Therefore, obesity, associated with the likelihood of subclinical bronchial hyper-reactivity, could justify the increased number of arousals in the group of patients. The influence of upper airways resistance syndrome cannot be excluded in spite of the normality of the apnea-hypopnea index and the absence of daytime sleepiness complaints among patients, in view of the fact that a specific device was not used during sleep recording (28).

The use of DeMeester criteria to analyze esophageal $\mathrm{pH}$ variability is justified given that this method considers the duration of events with $\mathrm{pH}<4$ as a key factor. In our view, this corresponds to the parameter that best discriminates physiological from pathological GER events $(29,30)$.

Regarding GER, 17 of the 31 (50\%) asthmatic patients were classified as DeMeester positive. The higher prevalence of orthostatic GER in both DeMeester-positive and -negative groups highlights the greater competence of the esophagogastric junction in the supine rather than in the orthostatic position (22,31). Furthermore, physiological GER events, which are less severe and rarely symptomatic, mainly occur in the orthostatic position, particularly after meals.

GER episodes occurred more frequently during wakefulness. During sleep, GER events are less common, and may reflect a dysfunction of the lower esophageal sphincter, leading to inflammation and erosion of the esophageal mucosa due to the continuous and prolonged contact with the gastric content (23) or to frequent modifications in esophageal $\mathrm{pH}$ (32). Even though the contact time between the esophageal mucosa and acid is a more important factor than the number of GER events, the total number of reflux episodes was taken into consideration in the present study in order to assess sleep alterations related to GER.

Despite the higher prevalence of wakefulness at the time of GER detection, $62 \%$ of the events were preceded by sleep, particularly stage 2 of non-REM sleep, showing that sleep alterations occurred at least one minute prior to the fall in esophageal $\mathrm{pH}$ to values of 4 or below. A further increase in arousals with modifications of sleep stages preceding GER events during stages 1 and 2 of non-REM sleep was a notable feature. As previously described, GER events were less frequent during REM sleep, a period during which secondary contractions of the esophagus might act as a protecting factor for the esophageal mucosa in contact with the acid refluxate $(2,33)$. Sleep alterations, at least one minute prior to the drop in esophageal $\mathrm{pH}$ to values of 4 or below, were independent of the duration of the GER event. Modifications in sleep to a light sleep architecture, characterized by arousals, lighter sleep stages or awakening after sleep onset, can be interpreted as a protection of the esophageal mucosa by permitting swallowing and heightened peristalsis, thereby avoiding prolonged local acidity and lesions to the esophageal mucosa (33).

The reports of sleep disruption in asthmatic patients could be attributed to asthma $(26,34), \operatorname{GER}(31,33)$, or to aggravation of asthma by GER events $(9,10,13,14,35)$. Even though the time-related association of GER and blood desaturation episodes was not detected in the present study, nor was exacerbation of asthma observed after GER events, the role of asthma in sleep fragmentation cannot be excluded $(26,34)$.

The impact of sleep $(12,34,36)$ or GER $(9,10,13,14,35)$ on day- or night-time asthma attacks remains unresolved. In a controlled study of 9 patients with asthma, Hughes et al. (4) failed to find a relationship between GER episodes and modification of respiratory sleep parameters, since GER episodes occurred mainly during arousals or awakening periods. In a study based on simultaneous and continuous recordings of $\mathrm{pH}$ and lower airway resistance, Tan et al. (16) was also unsuccessful in establishing any impact of GER on day- or night-time asthma attacks.

To the best of our knowledge, this is the first study highlighting sleep fragmentation preceding GER events in patients with asthma. Even though a cause and effect relationship between GER and sleep disruption cannot be fully established, it can be suggested that decreases in $\mathrm{pH}$ which precede GER detection by pHmetry (32) could have an impact on sleep architecture. The assessment of any

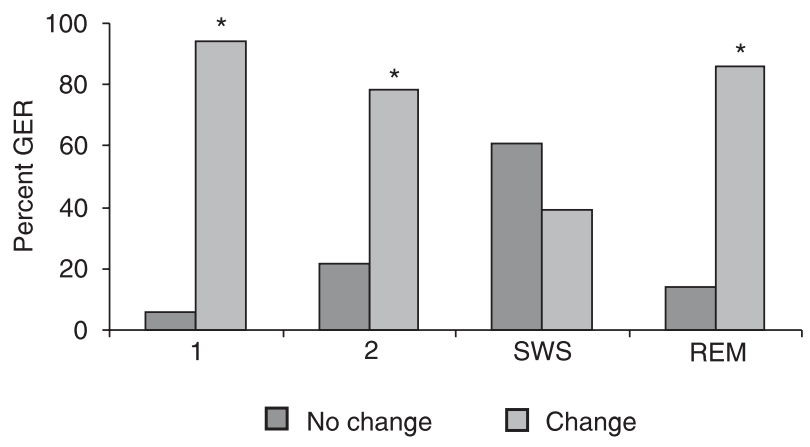

Figure 1. Association between gastroesophageal reflux (GER) and modification of sleep stages in the DeMeester-positive group. Dark columns $=$ no changes; light columns $=$ changes. SWS $=$ slow wave sleep; REM = rapid eye movement. ${ }^{*} P<0.01$ for percent GER during sleep stage 1, stage 2, REM sleep, but not SWS $\left(\chi^{2}\right.$ test). 
swallowing activity, the analysis of a longer sleep period preceding GER detection, and the inclusion of a sample of non-asthmatic individuals with GER symptoms would also be required to clarify the relationship between acid GER and sleep disruption.

A limitation of this study is related to the detection of GER events by monitoring esophageal $\mathrm{pH}$, since this detection can be biased by esophageal alkalization due to the presence of saliva, sub-mucous secretion, and the presence of food particles, oral infection or esophageal obstruction $(33,37)$. The combination of intraluminal impedance measurement (38) and esophageal $\mathrm{pH}$ monitoring has been considered to be the most appropriate method for the detection of GER (39), despite the fact that the classification of GER as acid and non-acid is theoretical, in view of the deleterious effects of both on the esophageal mucosa (40).

In conclusion, no difference in sleep architecture was detected between DeMeester-positive and -negative subgroups of asthmatic patients, and GER events were more frequent during the daytime and in wakefulness. When GER occurs during sleep, it can be related to sleep instability, preceding the detection of reflux. Further studies are needed to elucidate these findings.

\section{References}

1. Tibbling L. Epidemiology of gastro-oesophageal reflux disease. Scand J Gastroenterol 1984; 19: 14-15.

2. Orr WC. Gastrointestinal physiology. In: Kryger MH, Roth $\mathrm{T}$, Dement WC (Editors), Principles and practice of sleep medicine. 3rd edn. Philadelphia: WB Saunders; 2000. p 1113-1122.

3. Tabachnik E, Muller NL, Levison H, Bryan AC. Chest wall mechanics and pattern of breathing during sleep in asthmatic adolescents. Am Rev Respir Dis 1981; 124: 269-273.

4. Hughes DM, Spier S, Rivlin J, Levison H. Gastroesophageal reflux during sleep in asthmatic patients. J Pediatr 1983; 102: 666-672.

5. Orr WC. Reflux events and sleep: are we vulnerable? Curr Gastroenterol Rep 2006; 8: 202-207.

6. Goodall RJ, Earis JE, Cooper DN, Bernstein A, Temple JG. Relationship between asthma and gastro-oesophageal reflux. Thorax 1981; 36: 116-121.

7. Harding SM, Richter JE. The role of gastroesophageal reflux in chronic cough and asthma. Chest 1997; 111: 13891402.

8. Morales JEG, Hernandez LL, Spencer DG. Asma asociada a reflujo gastroesofágico. Alerg Mex 1998; 45: 16-21.

9. Field SK, Underwood M, Brant R, Cowie RL. Prevalence of gastroesophageal reflux symptoms in asthma. Chest 1996; 109: 316-322.

10. Harding SM. Nocturnal asthma: role of nocturnal gastroesophageal reflux. Chronobiol Int 1999; 16: 641-662.

11. Shigemitsu H, Afshar K. Nocturnal asthma. Curr Opin Pulm Med 2007; 13: 49-55.

12. Branscomb BV. The difficult asthmatic. Clin Chest Med 1984; 5: 695-713.

13. Valipour A, Makker HK, Hardy R, Emegbo S, Toma T, Spiro SG. Symptomatic gastroesophageal reflux in subjects with a breathing sleep disorder. Chest 2002; 121: 1748-1753.

14. Martin ME, Grunstein MM, Larsen GL. The relationship of gastroesophageal reflux to nocturnal wheezing in children with asthma. Ann Allergy 1982; 49: 318-322.

15. Davis RS, Larsen GL, Grunstein MM. Respiratory response to intraesophageal acid infusion in asthmatic children during sleep. J Allergy Clin Immunol 1983; 72: 393-398.
16. Tan WC, Martin RJ, Pandey R, Ballard RD. Effects of spontaneous and simulated gastroesophageal reflux on sleeping asthmatics. Am Rev Respir Dis 1990; 141: 1394-1399.

17. Asthma management and prevention. Global initiative for asthma. Ir Med J 2000; 1-39.

18. Moraes-Filho J, Cecconello I, Gama-Rodrigues J, Castro L, Henry MA, Meneghelli UG, et al. Brazilian consensus on gastroesophageal reflux disease: proposals for assessment, classification, and management. Am J Gastroenterol 2002; 97: 241-248.

19. Rechtschaffen A, Kales A. A manual of standardized terminology, techniques and scoring systems for sleep stages of human subjects. Los Angeles: BIS/BRI, UCLA Press, 1968.

20. Sleep-related breathing disorders in adults: recommendations for syndrome definition and measurement techniques in clinical research. The Report of an American Academy of Sleep Medicine Task Force. Sleep 1999; 22: 667-689.

21. American Sleep Disorders Association. EEG arousals: scoring rules and examples. Sleep 1992; 15: 173-184.

22. DeMeester TR, Johnson LF, Joseph GJ, Toscano MS, Hall AW, Skinner DB. Patterns of gastroesophageal reflux in health and disease. Ann Surg 1976; 184: 459-470.

23. Orr WC, Chen CL. Sleep and the gastrointestinal tract. Neurol Clin 2005; 23: 1007-1024.

24. Chinn S, Jarvis D, Burney P. Relation of bronchial responsiveness to body mass index in the ECRHS. European Community Respiratory Health Survey. Thorax 2002; 57: 1028-1033.

25. Shore SA, Johnston RA. Obesity and asthma. Pharmacol Ther 2006; 110: 83-102.

26. Janson C, De Backer W, Gislason T, Plaschke P, Bjornsson $E$, Hetta J, et al. Increased prevalence of sleep disturbances and daytime sleepiness in subjects with bronchial asthma: a population study of young adults in three European countries. Eur Respir J 1996; 9: 2132-2138.

27. Berger KI, Ayappa I, Chatr-Amontri B, Marfatia A, Sorkin IB, Rapoport DM, et al. Obesity hypoventilation syndrome as a spectrum of respiratory disturbances during sleep. Chest 2001; 120: 1231-1238.

28. Guilleminault C, Stoohs R, Clerk A, Cetel M, Maistros P. A 
cause of excessive daytime sleepiness. The upper airway resistance syndrome. Chest 1993; 104: 781-787.

29. Wiener GJ, Morgan TM, Copper JB, Wu WC, Castell DO, Sinclair JW, et al. Ambulatory 24-hour esophageal pH monitoring. Reproducibility and variability of $\mathrm{pH}$ parameters. Dig Dis Sci 1988; 33: 1127-1133.

30. Galmiche JP, Scarpignato C. Esophageal pH monitoring. Functional evaluation in esophageal disease. Front Gastrointest Res 1994; 22: 71-108.

31. Orr WC, Robinson MG, Johnson LF. The effect of esophageal acid volume on arousals from sleep and acid clearance. Chest 1991; 99: 351-354.

32. Theodoropoulos DS, Pecoraro DL, Lockey RF, Boyce HW $\mathrm{Jr}$, Bukantz SC. Visceral sensitivity in gastroesophageal reflux. Dig Dis Sci 2002; 47: 2554-2564.

33. Orr WC. Sleep and gastroesophageal reflux: what are the risks? Am J Med 2003; 115 (Suppl 3A): 109S-113S.

34. Bellia V, Cuttitta G, Insalaco G, Visconti A, Bonsignore G. Relationship of nocturnal bronchoconstriction to sleep stages. Am Rev Respir Dis 1989; 140: 363-367.
35. Cuttitta G, Cibella F, Visconti A, Scichilone N, Bellia V, Bonsignore G. Spontaneous gastroesophageal reflux and airway patency during the night in adult asthmatics. Am J Respir Crit Care Med 2000; 161: 177-181.

36. Ballard RD. Sleep, respiratory physiology, and nocturnal asthma. Chronobiol Int 1999; 16: 565-580.

37. Dent J, Dodds WJ, Friedman RH, Sekiguchi T, Hogan WJ, Arndorfer RC, et al. Mechanism of gastroesophageal reflux in recumbent asymptomatic human subjects. J Clin Invest 1980; 65: 256-267.

38. Orr WC, Craddock A, Goodrich S. Acidic and non-acidic reflux during sleep under conditions of powerful acid suppression. Chest 2007; 131: 460-465.

39. Mackie C, Hulks G, Cuschieri A. Enterogastric reflux and gastric clearance of refluxate in normal subjects and in patients with and without bile vomiting following peptic ulcer surgery. Ann Surg 1986; 204: 537-542.

40. Schindlbeck NE, Heinrich C, Stellaard F, Paumgartner G, Muller-Lissner SA. Healthy controls have as much bile reflux as gastric ulcer patients. Gut 1987; 28: 1577-1583. 